\title{
Captures of MFO-resistant Cydia pomonella adults as affected by lure, crop management system and flight
}

\author{
D. Bosch ${ }^{1 *}$ M.A. Rodríguez ${ }^{2}$ and J. Avilla ${ }^{3}$ \\ ${ }^{1}$ Institut Recerca i Tecnologia Agroalimentària (IRTA), Av. Alcalde Rovira \\ Roure, 191, 25198 Lleida, Spain: ${ }^{2}$ Universidad de Concepción, Castilla 160-C, \\ Concepción, Chile: ${ }^{3}$ Department of Crop and Forest Sciences, Agrotecnio, \\ University of Lleida, Rovira Roure, 191, 25198 Lleida, Spain
}

\begin{abstract}
The main resistance mechanism of codling moth (Cydia pomonella) in the tree fruit area of Lleida (NE Spain) is multifunction oxidases (MFO). We studied the frequency of MFOresistant adults captured by different lures, with and without pear ester, and flights in orchards under different crop management systems. The factor year affected codling moth MFO-resistance level, particularly in the untreated orchards, highlighting the great influence of codling moth migration on the spread of resistance in field populations. Chemical treatments and adult flight were also very important but mating disruption technique showed no influence. The second adult flight showed the highest frequency, followed by the first flight and the third flight. In untreated orchards, there were no significant differences in the frequency of MFO-resistant individuals attracted by Combo and BioLure. Red septa lures baited with pear ester (DA) captured sufficient insects only in the first generation of 2010, obtaining a significantly lower proportion of MFOresistant adults than Combo and BioLure. In the chemically treated orchards, in 2009 BioLure caught a significantly lower proportion of MFO-resistant adults than Combo during the first and third flight, and also than DA during the first flight. No significant differences were found between the lures or flights in 2010. These results cannot support the idea of a higher attractiveness of the pear ester for MFO-resistant adults in the field but do suggest a high influence of the response to the attractant depending on the management of the orchard, particularly with regard to the use of chemical insecticides.
\end{abstract}

Keywords: Cydia pomonella, mixed function oxidases, monitoring, pear ester, codlemone, crop management, adult flight

(Accepted 1 September 2015; First published online 26 October 2015)

\section{Introduction}

The codling moth, Cydia pomonella (L.) (Lepidoptera: Tortricidae), the main pest for apple, pear and walnut crops worldwide, has usually been controlled with insecticides. In Spain, organophosphates have been widely used for more than 30 years, but since the late 1990s, control of the pest through the use of insecticides has become more difficult

*Author for correspondence

Phone: +34 973702633

Fax: +34 973238301

E-mail: dolors.bosch@irta.cat due to the development of resistance (Bosch et al., 1999). At present, the control strategy for codling moth relies on the combined use of chemicals and mating disruption, especially in problematic orchards. Mating disruption has been applied extensively in the Ebro Valley since approximately 2007 and was applied in 2009 on more than 10,000 ha, of which, according to the distributors, 5450 ha were in Lleida, accounting for $68 \%$ of the production area. These figures were approximately the same in 2011 (Agriculture Department, personal communication). Pest population monitoring is a crucial component of any integrated pest management program. To monitor the phenology of codling moth in the field, the use of traps baited with $1 \mathrm{mg}$ (in chemical orchards) or $10 \mathrm{mg}$ (in mating disruption orchards) of (E,E)-8,10-dodecadien-1-ol (codlemone) has 
been extensive. However, in some cases, the lack of catches in the traps was unreliable (false negative), and particularly in mating disruption orchards it is necessary to check fruits to discard fruit infestations and not rely only on the trap catches. In Light et al. (2001), described a pear-derived kairomone (pear ester), ethyl (2E, 4Z)-2,4-decadienoate, which attracted C. pomonella male and female adults. Recently, the use of a synthetic lure baited with a combination of $3 \mathrm{mg}$ of this kairomone and $3 \mathrm{mg}$ of codlemone, CM-DA Combo ${ }^{\circledR}$, has been quickly replacing the use of $10 \mathrm{mg}$ codlemone lures in mating disruption orchards because it catches a higher number of moths (Torà et al., 2009; Joshi et al., 2011).

C. pomonella has developed resistance to a wide range of insecticides in almost all productive apple areas in the world (Sauphanor et al., 1998, 2000; Fuentes-Contreras et al., 2007; Ioratti et al., 2007; Reuveny \& Cohen, 2004; Stará \& Kocourek, 2007; Soleño et al., 2008, 2012; Knight, 2010; Rodríguez et al., 2010, 2012). A high frequency of resistant codling moth individuals has been detected in most of the problematic orchards in the tree fruit area of Lleida (NE Spain) (Rodríguez et al., 2011). Insect resistance may be due to the detoxification of the insecticides by three enzymatic complexes (mixed function oxidases (MFO), glutation transferases (GST) and esterases (EST)), or to structural changes (mutations) in the insecticide target protein that make the protein less sensitive to the insecticide (the acetylcholinesterase $(\mathrm{AChE})$ mutation in the case of organophosphates and carbamates, described by Cassanelli et al., (2006), and the knockdown resistance $(k d r)$ mutation in the voltage-gated sodium channel in the case of pyrethroids, described by Brun-Barale et al., (2005)). An increased production of MFO enzymes in adults and larvae was involved in the insecticide detoxification in all the field populations of the area tested (Rodríguez et al., 2010, 2012). GST were also detected, and EST were detected only in larvae (Rodríguez et al., 2011). These results cannot be generalized to all the codling moth populations in the area, but confirm that it is a real and increasing problem that may interfere with the management of the orchards.

Negative pleiotropic effects of insecticide resistance in codling moth, such as different development rates (Boivin et al., 2001, 2003a) and critical photoperiod for inducing diapause (Boivin et al., 2005), may affect the proportion of resistant insects present in the field during the different generations. These alterations have also been reported in other Lepidoptera species such as Plutella xylostella (L.) (Lepidoptera: Plutellidae) and Spodoptera exigua (Hübner) (Lepidoptera: Noctuidae) (Han et al., 2012; Ribeiro et al., 2014). Negative effects on sexual communication, such as low pheromone production by females and lower ability of males to detect the pheromone source, have also been detected (Poullot et al., 2001; Trimble et al., 2004). Nevertheless, Frérot et al. (1999) and Poullot et al. (2001) found that the level of attraction of the codling moth sex pheromone in the traps for released susceptible and resistant males in the orchards and in a wind tunnel was the same. Sauphanor et al. (2007) demonstrated a higher attraction of MFO-resistant male moths in pure kairomone-baited traps in apple orchards.

The aim of this work was to determine the frequency of MFO-resistant $C$. pomonella adults captured by different lures, with and without kairomone, and during the different flights in orchards under different crop management systems. The general state of the resistance in the area with regard to MFO activity is also noted.

\section{Material and methods}

\section{Insects and attractants}

Field codling moth catches were obtained in 20 and 25 field orchards in 2009 and 2010, respectively. Five orchards were classified as chemically untreated (UN, abandoned or organic orchards), eight as chemically treated $(\mathrm{CH})$ and 32 as pheromone mating disruption orchards supplemented with chemical insecticides $(\mathrm{MD}+\mathrm{CH})$. The plots were distributed throughout the production area of Lleida (Catalonia, NE Spain), with a maximum distance of $60 \mathrm{~km}$ between them. The Spanish susceptible strain (S_Spain) was used as a reference to determine the level above which an insect was recorded as resistant. This threshold was the highest 7-ethoxycoumarin-O-deethylation (ECOD) activity value corresponding to $90 \%$ of the S_Spain-analyzed individuals. S_Spain was collected from an abandoned apple orchard in Lleida in 1992, and it has been reared since then using a semiartificial dehydrated apple diet at the Sustainable Plant Protection Laboratory of the UdL-IRTA Centre for R\&D (University of Lleida, Institute for Food and Agricultural Research and Technology, Lleida, Spain).

The three codling moth attractants compared were BioLure $^{\mathrm{TM}} \mathrm{CM}$ 10X (Suterra) (named BioLure, loaded with $10 \mathrm{mg}$ of (E, E)-8, 10-dodecadien-1-ol [codlemone]), Pherocon CM-DA Combo ${ }^{\text {тм }}$ (named Combo, a mixture of $3.0 \mathrm{mg}$ of codlemone and $3.0 \mathrm{mg}$ of ethyl (2E, 4Z)-2,4- decadienoate) and red septa lures baited with pear ester (named DA, $3.0 \mathrm{mg}$ of pear ester). The traps were revised once a week and well maintained and the attractants were changed approximately every 8 weeks. The maximum period of time in which adults were analyzed was 4 weeks for each generation to avoid catching and analyzing adults from different generations in the same trap. The moment to begin the analysis was decided on the basis of the phenological model used in the area and was approximately 1 week after the prediction of the beginning of each adult flight. During these periods the adult field catches were taken to the laboratory twice a week in order to obtain as many live adults as possible.

\section{Enzymatic activity}

The adult MFO activity was determined with an in vivo protocol (Rodríguez et al., 2012) using ECOD in a black microplate of 96 wells. The dissected abdomens of the adults were placed individually in a well containing $100 \mu \mathrm{l}$ of phosphate buffer (50 mM, pH 7.2) and 7-ethoxycoumarin (7OH) $(0.4$ $\mathrm{mm})$. After $4 \mathrm{~h}$ of incubation at $30^{\circ} \mathrm{C}$, the reaction was stopped by adding $100 \mu \mathrm{l}$ of glycine buffer $\left(\mathrm{pH} 10.4,10^{-4} \mathrm{M}\right)$ with ethanol $(\mathrm{v} / \mathrm{v})$. Before the incubation a minimum of $10 \%$ of the wells of each microplate were used as controls and received the glycine buffer to stop the reaction. The ECOD activity was measured by fluorescence with a $380 \mathrm{~nm}$ excitation filter and a $465 \mathrm{~nm}$ emission filters and was expressed as pg of $7 \mathrm{OH}$ insect ${ }^{-1} \min ^{-1}$.

\section{Data analysis}

The differences between the absolute frequencies of resistant individuals according to the different attractants, adult flights, management systems and years were compared using a Pearson chi-square $\left(\chi^{2}\right)$ test. Moths were classified as resistant if their MFO enzyme activity exceeded the highest 

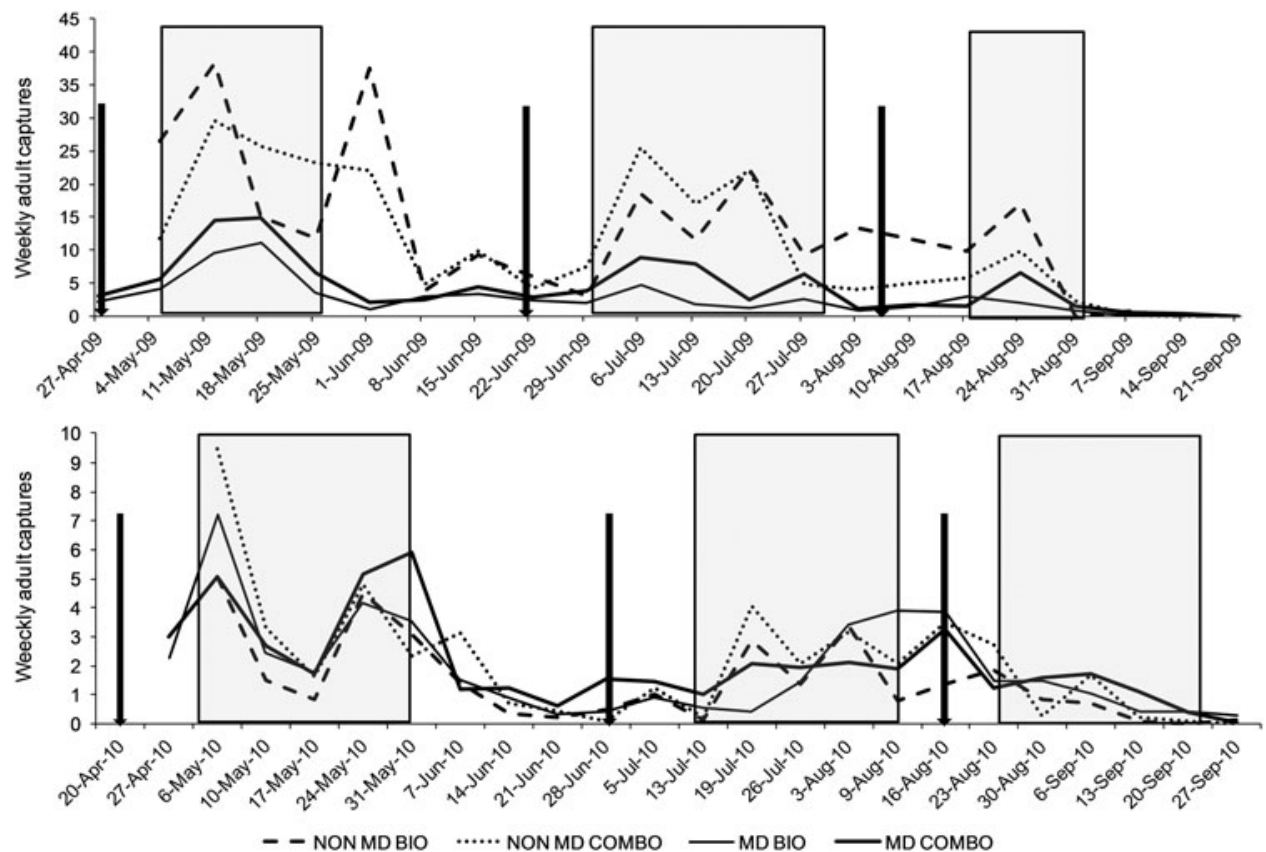

Fig. 1. Mean weekly codling moth adults caught in mating disruption (MD) and non-MD orchards using BioLureTM CM 10X and Pherocon CM-DA ComboTM lures and period of time (rectangle area) when the MFO activity was measured in each flight (gray area). Number of traps $=30$ (2009) and 58 (2010). Solid bars show the beginning of each generation.

activity value corresponding to $90 \%$ of S Spain individuals (Reyes et al., 2007).

\section{Results}

The three periods of codling moth trap catches in 2009 were 6-26 May, 30 June to 30 Julyand 18 August to 1 September. It was considered that the adults caught in these periods belonged to the first, second and third flights, respectively. In 2010, the three periods were 5-31 May, 13 July-16 August and 23 August-20 September (fig. 1). BioLure- and Combo-baited traps tracked in a similar way the moth flights during the two seasons in mating disruption and non-mating disruption orchards. In 2009, the number of catches was in general higher than in 2010 and the three flight peaks were also more evident in the flight curve. The flight curve obtained with DA is not represented in fig. 1 due to the low number of captures. The maximum number of catches per trap and week was recorded both years in non-mating disruption orchards, in Bio traps in 2009 and Combo traps in 2010, resulting in 38.3 and 9.5 moths, respectively. The second flight always showed a lower number of catches than the first, and the third flight was always very short, especially in 2009.

The percentages of MFO-resistant insects obtained in 2009 and 2010 in the orchards with different management systems using the attractants BioLure and Combo are shown in table 1. The value of the MFO threshold obtained using the S-Spain population was $23.92 \mathrm{pg} 7 \mathrm{OH}$ adult ${ }^{-1} \mathrm{~min}^{-1}$. In both years and with both attractants, the UN orchards obtained a significantly lower proportion of resistant insects than the $\mathrm{CH}$ and the $\mathrm{MD}+\mathrm{CH}$ orchards, and the $\mathrm{CH}$ orchards obtained the same proportion of resistant insects as the $\mathrm{CH}+\mathrm{MD}$ orchards (BioLure 2009, UN-CH, $\mathrm{dF}=1 ; \chi^{2}=7.24$ and $P=0.007$; UN$\mathrm{MD}+\mathrm{CH}, \quad \mathrm{dF}=1 ; \chi^{2}=10.00$ and $\mathrm{P}=0.002 ; \mathrm{CH}-\mathrm{MD}+\mathrm{CH}$,
$\mathrm{dF}=1 ; \chi^{2}=0.09$ and $P=0.762 ;$ BioLure 2010, $\mathrm{UN}-\mathrm{CH}, \mathrm{dF}=1$; $\chi^{2}=65.57$ and $P=5.60 \times 10^{-16} ; \quad \mathrm{UN}-\mathrm{MD}+\mathrm{CH}, \mathrm{dF}=1$; $\chi^{2}=121.96$ and $P=2.35 \times 10^{-28} ; \mathrm{CH}-\mathrm{MD}+\mathrm{CH}, \mathrm{dF}=1 ; \chi^{2}=0.14$ and $P=0.705$; Combo 2009, $\mathrm{UN}-\mathrm{CH}, \mathrm{dF}=1 ; \chi^{2}=33.39$ and $P=7.5 \times 10^{-9} ; \quad \mathrm{UN}-\mathrm{MD}+\mathrm{CH}, \quad \mathrm{dF}=1 ; \quad \chi^{2}=28.55 \quad$ and $P=9.15 \times 10^{-8} ; \mathrm{CH}-\mathrm{MD}+\mathrm{CH}, \mathrm{dF}=1 ; \chi^{2}=3.68$ and $P=0.055$; Combo 2010: UN-CH, $\mathrm{dF}=1 ; \chi^{2}=84.21$ and $P=4.46 \times 10^{-20}$; $\mathrm{UN}-\mathrm{MD}+\mathrm{CH}, \quad \mathrm{dF}=1 ; \quad \chi^{2}=103.80$ and $P=2.23 \times 10^{-24}$; $\mathrm{CH}-\mathrm{MD}+\mathrm{CH}, \mathrm{dF}=1 ; \chi^{2}=1.16$ and $P=0.282$ ). It can also be seen in table 1 that there was always numerically higher number of MFO-resistant moths in 2009 than in 2010. These differences were significant in the UN orchards for BioLure attractant and in the chemically treated orchards $(\mathrm{CH}$ and $\mathrm{CH}+\mathrm{MD})$ for Combo attractant (BioLure, UN orchards 2009-2010, $\mathrm{dF}=1$; $\chi^{2}=9.50$ and $P=0.002 ; \mathrm{CH}$ orchards 2009-2010, $\mathrm{dF}=1$; $\chi^{2}=0.04$ and $P=0.839 ; \mathrm{MD}+\mathrm{CH}$ orchards 2009-2010, $\mathrm{dF}=1 ; \chi^{2}=1.99$ and $P=0.158$; Combo, UN orchards 20092010, $\mathrm{dF}=1 ; \chi^{2}=2.04$ and $P=0.153 ; \mathrm{CH}$ orchards 2009-2010, $\mathrm{dF}=1 ; \chi^{2}=9.37$ and $P=0.002 ; \mathrm{MD}+\mathrm{CH}$ orchards 2009-2010, $\mathrm{dF}=1 ; \chi^{2}=18.84$ and $P=1.41 \times 10^{-5}$ ).

The frequencies of resistant individuals caught during the three adult flights in the orchards with different management systems during the 2 years of the assay are shown in table 2 . There were no significant differences between the frequency of MFO-resistant adults captured in the different flights in the UN orchards, in spite of the higher proportion of resistant adults in the second flight in both years $(2009,1$ st-2nd flight, $\mathrm{dF}=1 ; \chi^{2}=1.30$ and $P=0.255 ; 2010,1$ st -2 nd flight, $\mathrm{dF}=1$; $\chi^{2}=2.86$ and $P=0.091 ; 1$ st-3rd flight, $\mathrm{dF}=1 ; \chi^{2}=0.11$ and $P=0.745 ; 2$ nd-3rd flight, $\mathrm{dF}=1 ; \chi^{2}=3.32$ and $P=0.069$ ). In the $\mathrm{CH}$ and $\mathrm{CH}+\mathrm{MD}$ orchards, the second adult flight was the one with the highest proportion of MFO-resistant adults and the differences from the first flight were always significant. The third flight was the one with the lowest frequencies 
Table 1. Percentage of MFO-resistant codling moth adults caught in 2009 and 2010 in orchards with different management systems in the area of Lleida in traps baited with BioLure ${ }^{\mathrm{TM}} \mathrm{CM} 10 \mathrm{X}$ and Pherocon CM-DA Combo ${ }^{\mathrm{TM}}$.

\begin{tabular}{|c|c|c|c|c|c|c|c|}
\hline \multirow[t]{2}{*}{ Lure } & \multirow[t]{2}{*}{ Management system } & \multicolumn{3}{|l|}{2009} & \multicolumn{3}{|l|}{2010} \\
\hline & & No. orchards & No. insects & $\begin{array}{l}\text { Resistance } \\
\text { frequency }(\%)\end{array}$ & No. orchards & No. insects & $\begin{array}{l}\text { Resistance } \\
\text { frequency (\%) }\end{array}$ \\
\hline & $\mathrm{CH}$ & 2 & 135 & $71.1 \mathrm{~b} \mathrm{~A}$ & 6 & 103 & $69.9 \mathrm{~b} \mathrm{~A}$ \\
\hline & $\mathrm{MD}+\mathrm{CH}$ & 16 & 367 & $72.5 \mathrm{~b} \mathrm{~A}$ & 16 & 478 & $68.0 \mathrm{~b} \mathrm{~A}$ \\
\hline \multirow[t]{2}{*}{ Combo } & UN & 2 & 32 & 34.4 a $\mathrm{A}$ & 3 & 211 & 22.7 a $\mathrm{A}$ \\
\hline & $\mathrm{CH}$ & 2 & 123 & $84.6 \mathrm{~b} \mathrm{~A}$ & 6 & 178 & 69.1 b B \\
\hline
\end{tabular}

$\mathrm{UN}$, untreated orchards; $\mathrm{CH}$, chemically treated orchards; $\mathrm{MD}+\mathrm{CH}$, mating disruption orchards supported by chemical treatments.

For each attractant, numbers followed by the same lower case letter on the same column are not significantly different $(P<0.05)$. For each attractant and management system, numbers followed by the same upper case letter on the same line are not significantly different $(P<0.05)$.

Table 2. Percentage of MFO-resistant codling moth adults caught in the three flights of the years 2009 and 2010 in orchards with different management systems in the area of Lleida.

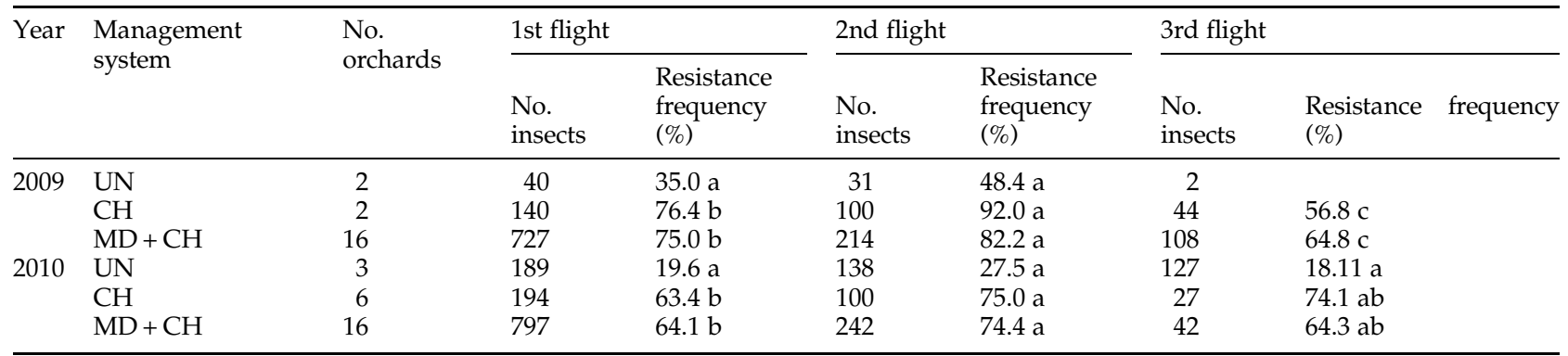

$\mathrm{UN}$, untreated orchards; $\mathrm{CH}$, chemically treated orchards; $\mathrm{MD}+\mathrm{CH}$, mating disruption orchards supported by chemical treatments.

For each year and management system, numbers followed by the same lower case letter on the same line are not significantly different $(P<0.05)$.

of MFO-resistant adults in 2009, but in 2010 it was the first flight which had the lowest frequency (2009, CH orchards, 1st-2nd flight, $\mathrm{dF}=1 ; \chi^{2}=9.99$ and $P=0.002 ; 1$ st-3rd flight, $\mathrm{dF}=1 ; \quad \chi^{2}=6.35$ and $P=0.012 ; 2$ nd-3rd flight, $\mathrm{dF}=1$; $\chi^{2}=24.83$ and $P=6.27 \times 10^{-7} ; 2009, \mathrm{MD}+\mathrm{CH}$ orchards: 1 st2nd flight, $\mathrm{dF}=1 ; \chi^{2}=5.85$ and $P=0.016 ; 1$ st-3rd flight, $\mathrm{dF}=1 ; \chi^{2}=4.99$ and $P=0.025 ;$ 2nd-3rd flight, $\mathrm{dF}=1$; $\chi^{2}=13.22$ and $P=2.77 \times 10^{-4} ; 2010, \mathrm{CH}$ orchards, 1 st-2nd flight, $\mathrm{dF}=1 ; \chi^{2}=4.04$ and $P=0.045 ; 1$ st-3rd flight, $\mathrm{dF}=1$; $\chi^{2}=1.18$ and $P=0.277 ; 2$ nd-3rd flight, $\mathrm{dF}=1 ; \chi^{2}=0.01$ and $P=0.922 ; 2010, \mathrm{MD}+\mathrm{CH}$ orchards, 1 st -2 nd flight, $\mathrm{dF}=1$; $\chi^{2}=8.78$ and $P=0.003 ; 1$ st -3 rd flight, $\mathrm{dF}=1 ; \chi^{2}=5.03 \times 10^{-4}$ and $P=0.982 ; 2$ nd-3rd flight, $\mathrm{dF}=1 ; \chi^{2}=1.85$ and $P=0.174$ ).

As the year, the adult flight and the application of treatments in the orchards influenced the amount of MFO-resistant codling moths in the field, all these factors were taken into account to study the influence of the lure in the frequency of MFO-resistant individuals captured in the traps (figs 2 and 3). From this moment the $\mathrm{CH}$ and $\mathrm{CH}+\mathrm{MD}$ orchards were considered as chemically treated orchards.

There were no significant differences in the frequency of MFO-resistant individuals attracted by Combo and BioLure in the UN orchards in either of the 2 years. The attractant DA captured enough insects to compare with the other two attractants only in the first flight of 2010, obtaining a significant lower proportion of MFO-resistant adults than Combo and BioLure (2009, 1st flight, Combo-BioLure, $\mathrm{dF}=1 ; \chi^{2}=1.39$ and $P=0.238 ; 2$ nd flight, Combo-BioLure, $\mathrm{dF}=1 ; \chi^{2}=0.89$ and $P=0.345 ; 2010$, 1st flight, Combo-BioLure, $\mathrm{dF}=1$; $\chi^{2}=0.08$ and $P=0.784 ;$ Combo-DA, $\mathrm{dF}=1 ; \chi^{2}=6.83$ and $P=0.009 ;$ BioLure-DA, $\mathrm{dF}=1 ; \chi^{2}=6.24$ and $P=0.012 ; 2$ nd flight, Combo-BioLure, $\mathrm{dF}=1 ; \chi^{2}=0.42$ and $P=0.518 ; 3 \mathrm{rd}$ flight, Combo-BioLure, $\mathrm{dF}=1 ; \chi^{2}=0.38$ and $P=0.540$ ). In the 2009, chemically treated orchards BioLure caught a significantly lower proportion of MFO-resistant adults than Combo during the first and third flights and also than DA during the first flight. There were no significant differences between the frequency of MFO-resistant insects attracted by the different lures during the three flights in 2010 (2009, 1st flight, Combo-BioLure, $\mathrm{dF}=1 ; \chi^{2}=4.27$ and $P=0.039$; Combo-DA, $\mathrm{dF}=1 ; \chi^{2}=0.53$ and $P=0.466$; BioLure-DA, $\mathrm{dF}=1 ; \chi^{2}=3.90$ and $P=0.048 ; 2$ nd flight, Combo-BioLure, $\mathrm{dF}=1 ; \chi^{2}=0.49$ and $P=0.482 ;$ Combo-DA, $\mathrm{dF}=1 ; \chi^{2}=0.16$ and $P=0.688$; BioLure-DA, $\mathrm{dF}=1 ; \chi^{2}=0.003$ and $P=0.956$; 3rd flight, Combo-BioLure, $\mathrm{dF}=1 ; \chi^{2}=3.96$ and $P=0.047$; 2010, 1st flight, Combo-BioLure, $\mathrm{dF}=1 ; \chi^{2}=0.29$ and $P=0.593 ; \quad$ Combo-DA, $\mathrm{dF}=1 ; \chi^{2}=0.05$ and $P=0.831$; BioLure-DA, $\mathrm{dF}=1 ; \chi^{2}=0.32$ and $P=0.572 ; 2$ nd flight, Combo-BioLure, $\mathrm{dF}=1 ; \chi^{2}=0.21$ and $P=0.650$; Combo-DA, $\mathrm{dF}=1 ; \chi^{2}=2.55$ and $P=0.110 ;$ BioLure-DA, $\mathrm{dF}=1 ; \chi^{2}=2.06$ and $P=0.152 ; 3$ rd flight, Combo-BioLure, $\mathrm{dF}=1 ; \chi^{2}=0.02$ and $P=0.883)$.

\section{Discussion}

The MFO-resistance level of codling moth in the field was affected by the year. In general, the frequency of 


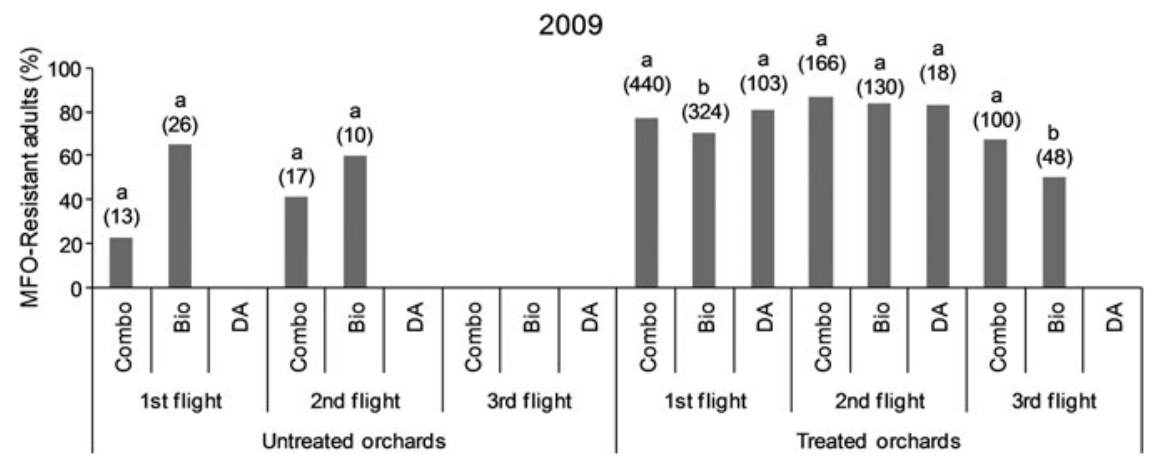

Fig. 2. Percentage of MFO-resistant codling moth adults in the three field flights captured by delta traps lured with Pherocon CM-DA ComboTM, BioLureTM CM 10X and the pear ester DA (3.0 mg of pear ester) in two untreated and 18 treated orchards of the production area of Lleida during the year 2009. Number within the brackets represents the number of insects processed.

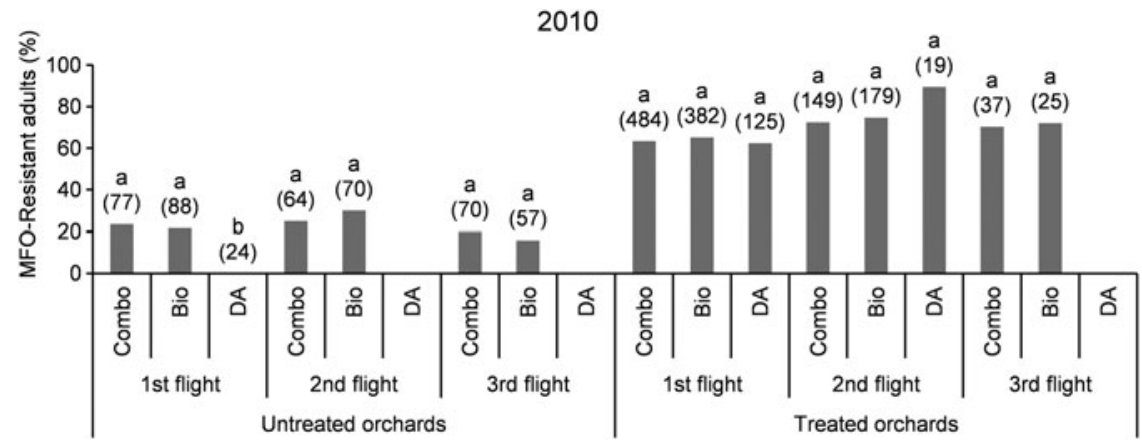

Fig. 3. Percentage of MFO-resistant codling moth adults in the three field flights captured by delta traps lured with Pherocon CM-DA ComboTM, BioLureTM CM 10X and the pear ester DA (3.0 mg of pear ester) in untreated (three orchards) and treated orchards (22 orchards) of the production area of Lleida during the year 2010. Numbers within the brackets represent the number of insects processed.

MFO-resistant adults was higher in 2009 than in 2010. A higher number of catches obtained during the year usually led to a higher number of chemical treatments to control the pest and consequently a higher selection of insecticide-resistant individuals. The UN orchards, in this case abandoned and organic orchards, did not use insecticides to control codling moth and the organic orchards based their strategy on mating disruption and carpovirusine treatments. The frequency of MFO-resistant codling moth adults was higher in 2009 and lower in 2010 in the UN orchards. The lower number of captures obtained in 2009 may influence this result, but this result may also point out the great influence that can have the codling moth migration in the spread of resistance in field populations. Several dispersal behavior studies using mark-release-recapture and immunomarking methodologies found that the main proportion of adults dispersed within 60-80 m (Keil et al., 2001; Margaritopoulos et al., 2012), although a small proportion (7.4-20.0\%) was able to fly up to several kilometers as an adaptive trait, in order to survive in case of habitat deterioration (Schumacher et al., 1997a , b; Keil et al., 2001). This capacity of dispersion may be responsible for the fluctuations in the presence of resistant adults in the untreated orchards which, in our area, were surrounded by treated orchards.

Presence or absence of chemical treatments in the orchards is the main factor affecting the frequency of MFO-resistant adults. No difference was found between orchards using codling moth mating disruption and those not using it. Mating disruption used without the support of chemical treatments is not sufficiently effective in the area of Lleida to control the pest because of an important constraint of this technique: the need for low population levels (Moffit \& Westigard, 1984; Vickers \& Rothschild, 1991). Therefore, the use of insecticides combined with mating disruption did not in general lead to a significant reduction in resistance selection.

The phenology of codling moth in the field depends on major abiotic factors such as temperature and day length (Shel'Deshova, 1967; Riedl \& Croft, 1978; Steinberg et al., 1992) and biotic factors such as food availability (Brown et al., 1979; Riedl, 1983). However, the application of insecticides may condition its phenology and cause behavioral and/or physiological damage to insects besides death (Buckingham et al., 2005; Davies et al., 2007; Casida, 2009; Tan et al., 2014). The different moth adult flights showed a significantly different proportion of MFO-resistant adults in chemically treated orchards $(\mathrm{CH}$ and $\mathrm{MD}+\mathrm{CH})$. The second adult flight had the highest frequency of resistant individuals. These adults came from the surviving neonate larvae affected by the chemical treatments applied in the orchards during the entire first adult flight. The first flight in the area of the assay lasted approximately 9 weeks in 2009 and 11 weeks in 2010, while the second and third flights lasted approximately 6-7 weeks and 4-5 weeks, respectively. The longer duration of the first flight usually means, in case of a medium or high population in the orchard, that a higher amount of insecticide 
treatments may be applied. The frequency of MFO-resistant first adult flight depends on the frequency of the secondand third-generation diapausing larvae of the previous year, and on their proportion, which in turn depends on the annual variation in climate conditions. Boivin et al. (2004) stated that if the third generation in the field was not successfully completed, due to a sudden shorter summer or harvest, the second-generation diapausing cohorts were the only source for the genetic pool of the next spring generation. Also, in winter negative pleiotropic effects on the codling moth diapausing larvae associated with enhanced MFO levels may be expected (Boivin et al., 2001). Deleterious effects in MFO-resistant pupae during diapause were also proved in Helicoverpa armigera (Hübner) (Daly, 1993). The third adult flight showed the lowest frequency of MFO-resistant adults. Homozygous MFO-resistant individuals have slower developmental rates and earlier diapause timing than susceptible homozygotes and heterozygotes (Boivin et al., 2003b, 2004). We may therefore assume that the third flight was mainly formed by these more susceptible individuals that were able to produce an additional generation. Data from 2010 may also support this conclusion. The proportion of MFO-resistant individuals in 2010 was lower than in 2009, therefore a lower number of homozygous individuals can be expected in the field justifying the lack of significant differences against the three adult flights.

In 2009, treated orchards, BioLure was less attractive than the other lures containing pear ester during the first and the third generation, but these results were not confirmed in 2010, when all the attractants captured the same frequency of MFO-resistant adults. Conversely, in UN orchards BioLure always caught the same frequency of MFO-resistant individuals as Combo, but in 2010 in first flight - the only flight with sufficient captures - DA caught the lowest frequency of resistant insects. Sauphanor et al. (2007) found significantly higher mean MFO activity in first flight male adults captured in field traps baited with $40 \mathrm{mg}$ of pear ester than in those captured in traps baited with $10 \mathrm{mg}$ of codlemone. The differences remained in the chemical and organic orchards in both years. However, some differences in the tests may have influenced the results. Sauphanor et al. (2007) used the mean pg of $7 \mathrm{OH}$ formed per adult and minute to compare the level of resistance of the different orchard populations, whereas we considered that some high values in a few insects may significantly modify the average and preferred to use the frequency of resistant individuals as an indicator of the level of resistance in the orchards. Furthermore, in our study previous results led us to include females in the analysis. Rodríguez et al. (2010), in field adults from different orchards in the same production area, found no clear tendency in the enzymatic activity between sexes. The differences appeared at random and were due to higher values for males or for females depending on the orchards. Therefore, due to the low number of captures traditionally obtained with the pear ester alone in our area (Bosch \& Avilla, 2005), we decided to include the females to increase the number of captured adults analyzed in the DA attractant.

The opposite tendency in the attraction of MFO-resistant adults of pear ester in treated and untreated orchards may be influenced by the sublethal effect of insecticides. A list of identified effects of insecticide sublethal doses on the olfactory system of agricultural insect pests can be found in Tricoire-Leignel et al. (2012). Field treatments with the ecdysteroid agonists tebufenozide and methoxyfenozide decrease male responses to pheromone in the tortricid moths Choristoneura fumiferana, C. rosaceana, Argyrotaenia velutinana, C. pomonella and Grapholita molesta (Hoelscher \& Barrett, 2003; Dallaire et al., 2004; Barrett, 2008). Barrett (2010) found that methoxyfenozide also disrupted responses of codling moth males to pear ester. Treatments with the organophosphate malathion decrease the ability of corn borer Ostrinia furnacalis males to respond to the female pheromone (Zhou et al., 2005) and some pyrethroids disrupt the male attraction to the sex pheromone in the pink bollworm, Pectinophora gossypiella, the corn borer O. furnacalis and the noctuid Trichoplusia ni (Haynes \& Baker, 1985; Haynes et al., 1986; Moore, 1988; Clark \& Haynes, 1992; Wei \& Du, 2004). In addition, pesticides could affect in a different way the chemical communication of susceptible and resistant insects. The alteration of sexual communication, a fitness component, imposed by insecticide resistance in some moth species is expected to contribute to the decline of resistance in the absence of insecticide (Delisle \& Vincent, 2002). Sauphanor et al. (2007) found that pear ester produced an enhanced or altered response in wind tunnel in codling moth adults with MFO and $k d r$ resistance mechanisms. However, this response of $k d r$-resistant genotipes was not confirmed in the field. The enzymatic system mainly involved in insecticide detoxification in Spanish codling moth field populations, monooxygenases (Rodríguez et al., 2012), is also involved in the recognition of the host-plant (Feyresen, 1999). Trimble et al. (2004) found that the proportion of azinphos-methyl-resistant males of obliquebanded leafrollers (C. rosaceana (Harris)) that located a synthetic pheromone source in the orchard was $32 \%$ lower than the proportion of susceptible males, while in the flight tunnel a similar proportion of susceptible and resistant males located the source. According to Sauphanor et al. (2007), the sensory or behavioral response to a semiochemical compound is more likely to be altered by a mutation affecting the nervous system than by a metabolic resistance.

Summarizing, in the field populations of the study area a general enhanced enzymatic MFO activity in all the chemically treated orchards was demonstrated. The frequency of MFO-resistant codling moth adults was more stable in these orchards than in the untreated orchards that showed a higher variability depending on the general frequency of MFO resistance in the year. These results proved the importance of dispersion of resistant adults in a neighboring production area. The role of the chemically untreated orchards as a reservoir of insecticide susceptible individuals must to be demonstrated. Our results cannot support the idea of a higher attractiveness of the pear ester for MFO-resistant adults in the field and point to a different response depending on the management of the orchards. In addition, the target mutations in sodium channel gene $(k d r)$ and AChE1 proteins (AChE), respectively responsible for pyrethroid and organophosphate resistance, have been detected extensively in the Ebro Valley production area (Bosch et al., 2014). Further research is needed to clarify the possible incidence of a higher proportion of individuals in the field with the mutations ( $k d r$ and $\mathrm{AChE}$ ) in response to different semiochemical compounds.

\section{Acknowledgements}

The authors would like to express their sincere thanks to the fruit growers who gave us access to their orchards and to the grower advisors of the different areas (ADV technicians) 
who helped identifying the best orchards for the assay. This study was supported by grants AGL2010-17486/AGR and AGL2013-49164 of the Spanish Ministry for Science and Innovation.

\section{References}

Barrett, B.A. (2008) Assessment of methoxyfenozide exposure on the sexual attractiveness and responsiveness of adult codling moth, Cydia pomonella (L.), in small orchard blocks. Pest Management Science 64, 916-922.

Barrett, B.A. (2010) Exposure to methoxyfenozide treated surfaces reduces the responsiveness of adult male codling moth (Lepidoptera: Tortricidae) to codlemone and pear ester lures in a wind tunnel. Journal of Economic Entomology 103, 1704-1710.

Boivin, T., Chabert-d'Hières, C., Bouvier, J.C., Beslay, D. \& Sauphanor, B. (2001) Pleiotropy of insecticide resistance in the codling moth, Cydia pomonella. Entomolgia Experimentalis et Applicata 99, 381-386.

Boivin, T., Bouvier, J.C., Chadoeuf, J., Beslay, D. \& Sauphanor, B. (2003a) Constraints on adaptative mutations in the codling moth Cydia pomonella (L.): measuring fitness trade-offs and natural selection. Heredity 90, 107-113.

Boivin, T., Bouvier, J.C., Beslay, D. \& Sauphanor, B. (2003b) Phenological segregation of insecticide-resistant genotypes in the codling moth Cydia pomonella (Lepidoptera: Tortricidae): a case study of ecological divergences associated with adaptive changes in populations. Genetical Research 81, 177.

Boivin, T., Bouvier, J.C., Beslay, D. \& Sauphanor, B. (2004) Variability in diapause propensity within populations of temperate insect species: interactions between insecticide resistance genes and photoperiodism. Biological Journal of the Linnean Society 83, 341-351.

Boivin, T., Bouvier, J.C., Chadoeuf, J., Beslay, D. \& Sauphanor, B. (2005) Modelling the interactions between phenology and insecticide resistance genes in the codling moth Cydia pomonella. Pest Management Science 61, 53-67.

Bosch, D. \& Avilla, J. (2005) Manejo de fincas en confusión sexual de carpocapsa Cydia pomonella (L.) mediante trampas de feromona y de (2E, 4Z)-2,4-decadienoato de etilo. p. 47 in Book of Abstracts of the IV Congreso Nacional de Entomología Aplicada - X Jornadas Científicas de la Sociedad Española de Entomología Aplicada organisez by Sociedad Española de Entomologia Aplicada, 17-21 October 2005, Bragança, Portugal.

Bosch, D., Voltes, M.T., Riedl, H., Torà, R., Sarasúa, M.J. \& Avilla, J. (1999) Evaluación de la resistencia de poblaciones españolas de carpocapsa (Cydia pomonella L.) a metil-azinfos. Phytoma España 109, 40-51.

Bosch, D., Avilla, J. \& Rodríguez, M.A. (2014) Occurrence of target-site mutations and PSMO enzymatic detoxification in adults of codling moth, Cydia pomonella (L.), from Spanish field populations. in Book of Abstracts of the Joint Meeting of the sub-Groups "Pome fruit arthropods" and "Stone fruits", 6-9th October, Vienna, Austria.

Brown, G.C., Berryman, A.A. \& Bogyo, T.P. (1979) Densitydependent induction of diapause in the codling moth, Cydia pomonella (Olthreutinae; Tortricidae). Canadian Entomologist 111, 431-433.

Brun-Barale, A., Bouvier, J.C., Pauron, D., Bergé, J.B. \& Sauphanor, B. (2005) Involvement of a sodium channel mutation in pyrethroid resistance in Cydia pomonella (L.) and development of diagnostic test. Pest Management Science 61, 549-554.

Buckingham, S.D., Biggin, P.C., Sattelle, B.M., Brown, L.A. \& Sattelle, D.B. (2005) Insect GABA receptors: splicing, editing, and targeting by antiparasitic sand insecticides. Molecular Pharmacology 68, 942-951.

Casida, J.E. (2009) Pest toxicology: the primary mechanisms of pesticide action. Chemical Research in Toxicology 22, 609-619.

Cassanelli, S., Reyes, M., Rault, M., Manicardi, G.C. \& Sauphanor, B. (2006) Acetylcholinesterase mutation in an insecticide-resistant population of the codling moth Cydia pomonella (L.). Insect Biochemistry Molecular Biology 36, 642-653.

Clark, D. \& Haynes, K. (1992) Sublethal effects of cypermethrin on chemical communication, courtship, and oviposition in the cabbage-looper (Lepidoptera, Noctuidae). Journal of Economic Entomology 85, 1771-1778.

Dallaire, R., Labrecque, A., Marcotte, M., Bauce, E. \& Delisle, J. (2004) The sublethal effects of tebufenozide on the precopulatory and copulatory activities of Choristoneura fumiferana and C. rosaceana. Entomologia Experimentalis et Applicata 112, 169-181.

Daly, J.C. (1993) Ecology and genetics of insecticide resistance in Helicoverpa armigera: interactions between selection and gene flow. Genetica 90, 217-226.

Davies, T.G., Field, L.M., Usherwood, P.N. \& Williamson, M.S. (2007) DDT, pyrethrins, pyrethroids and insect sodium channels. IUBMB Life 59, 151-162.

Delisle, J. \& Vincent, C. (2002) Modified pheromone communication associated with insecticidal resistance in the obliquebanded leafroller, Choristoneura rosaceana (Lepidoptera: Tortricidae). Chemical Ecology 12, 47-51.

Feyresen, R. (1999) Insect P450 enzymes. Annual Review of Entomology 44, 507-533.

Frérot, B., Beslay, D., Malosse, C., Renou, M., Coupard, H., Bouvier, J.C. \& Sauphanor, B. (1999) Insecticide resistance and sexual pheromones in codling moth, Cydia pomonella L. pp. 97-105 in Proceedings of the fifth International Conference on Pests in Agriculture organized by Association Nationale de Protection des Plantes, 7-9 December 1999, Montpellier, France.

Fuentes-Contreras, E., Reyes, M., Barros, W. \& Sauphanor, B. (2007) Evaluation of azinphos-methyl resistance and activity of detoxifying enzymes in codling moth (Lepidoptera: Tortricidae) from Central Chile. Journal of Economic Entomology 100, 551-556.

Han, W., Zhang, S., Shen, F., Liu, M., Ren, C. \& Gao, X. (2012) Residual toxicity and sublethal effects of chlorantraniliprole on Plutella xylostella (Lepidoptera: Plutellidae). Pest Management Science 68, 1184-1190.

Haynes, K. \& Baker, T. (1985) Sublethal effects of permethrin on the chemical communication-system of the pinkbollworm moth, Pectinophora gossypiella. Archives of Insect Biochemistry and Physiology 2, 283-293.

Haynes, K., Li, W. \& Baker, T. (1986) Control of pink-bollworm moth (Lepidoptera, Gelechiidae) with insecticides and pheromones (attracticide) - lethal and sublethal effects. Journal of Economic Entomology 7, 1466-1471.

Hoelscher, J. \& Barrett, B. (2003) Effects of methoxyfenozide treated surfaces on the attractiveness and responsiveness of adult leafrollers. Entomologia Experimentalis et Applicata 107, 133-140.

Ioratti, C., Tasin, M., Charmillot, J.P., Reyes, M. \& Sauphanor, B. (2007) Early detection of resistance to tebufenocide in field populations of Cydia pomonella L.: methods and mechanisms. Journal of Applied Entomology 131, 453-459. 
Joshi, N.K., Hull, L.A., Rajotte, E.G., Krawczyk, G. \& Bohnenblust, E. (2011) Evaluating sex-pheromone and kairomone based lures for attracting codling moth adults in mating disruption versus conventionally managed apple orchards in Pennsylvania. Pest Management Science 67, 13321337.

Keil, S., Gu, H.N. \& Dorn, S. (2001) Response of Cydia pomonella to selection on mobility: laboratory evaluation and field verification. Ecological Entomology 26, 495-501.

Knight, A.L. (2010) Cross-resistance between azinphos-methyl and acetamiprid in populations of codling moth, Cydia pomonella (L.) (Lepidoptera: Tortricidae), from Washington State. Pest Management Science 66, 865-874.

Light, D.M., Knight, A.L., Henrick, C.A., Rajapaska, D., Lingren, B., Dickens, J.C., Reynolds, K.M., Buttery, R.G., Merrill, G., Roitman, J. \& Campbell, B.C. (2001) A pear derived kairomone with pheromonal potency that attracts male and female codling moth, Cydia pomonella (L.). Naturwissenschaften 88, 333-338.

Margaritopoulos, J.T., Voudouris, C.C., Olivares, J., Sauphanor, B., Mamuris, Z., Tsitsipis, J.A. \& Franck, P. (2012) Dispersal ability in codling moth: mark-release-recapture experiments and kinship analysis. Agricultural and Forest Entomology 14, 399-407.

Moffit, H.R. \& Westigard, P.H. (1984) Suppression of the codling moth (Lepidoptera: Tortricidae) population on pears in southern Oregon through mating disruption with sex pheromone. Journal of Economic Entomology 77, 1513-1519.

Moore, R. (1988) Inhibition of chemical communication between male and female bollworms (Lepidoptera, Noctuidae) by sublethal amounts of permethrin. Journal of Economic Entomology 81, 78-82.

Poullot, D., Beslay, D., Bouvier, J.C. \& Sauphanor, B. (2001) Is attract and kill technology potent against resistant Lepidoptera? Pest Management Science 57, 729-736.

Reuveny, H. \& Cohen, E. (2004) Resistance of the codling moth Cydia pomonella (L.) (Lep., Tortricidae) to pesticides in Israel. Journal of Applied Entomology 128, 645-651.

Reyes, M., Frank, P., Charmillot, J.P., Ioriatti, C., Olivares, J., Pasqualini, E. \& Sauphanor, B. (2007) Diversity of insecticide resistance mechanisms and spectrum in European populations of the codling moth, Cydia pomonella. Pest Management Science 63, 890-902.

Ribeiro, L.M.S., Wanderley-Teixeira, V., Ferreira, H.N., Teixeira, A.A.C. \& Siqueira, H.A.A. (2014) Fitness costs associated with field evolved resistance to chlorantraniliprole in Plutella xylostella (Lepidoptera: Plutellidae). Bulletin of Entomological Research 104, 88-96.

Riedl, H. (1983) Analysis of codling moth phenology in relation to latitude, climate and food availability. pp. 233-252 in Brown, V.K. \& Hodek, I., (Ed.) Diapause and Life Cycle Strategies in Insects. The Hague, Dr. W. Junk.

Riedl, H. \& Croft, B.A. (1978) The effects of photoperiod and effective temperatures on the seasonal phenology of the codling moth (Lepidoptera: Tortricidae). Canadian Entomologist 110, 455-470.

Rodríguez, M.A., Bosch, D., Sauphanor, B. \& Avilla, J. (2010) Susceptibility to organophosphate insecticides and activity of detoxifying enzymes Spanish populations of Cydia pomonella (Lepidoptera: Tortricidae). Journal of Economic Entomology 103, 482-491.

Rodríguez, M.A., Bosch, D. \& Avilla, J. (2011) Resistance of Spanish codling moth (Cydia pomonella (L.), Lepidoptera: Tortricidae) populations to insecticides and activity of detoxifying enzymatic systems. Entomologia Experimentalis et Applicata 138, 184-192.

Rodríguez, M.A., Bosch, D. \& Avilla, J. (2012) Azinphos-methyl and carbaryl resistance in adults of the codling moth (Cydia pomonella (L.), Lepidoptera: Tortricidae) from Northeastern of Spain. Pesticide Biochemistry and Physiology 103, 43-48.

Sauphanor, B., Brosse, V., Monier, C. \& Bouvier, J.C. (1998) Differencial ovicidal and larvicidal resistance to benzoylureas in the codling moth, Cydia pomonella. Entomologia Experimentalis et Applicata 88, 247-253.

Sauphanor, B., Brosse, V., Bouvier, J.C., Speich, P., Micoud, A. \& Martinet, C. (2000) Monitoring resistance to diflubenzuron and deltametrin in French codling moth populations (Cydia pomonella). Pest Management Science 56, 74-82.

Sauphanor, B., Franck, P., Lasnier, T., Toubon, J.F., Beslay, D., Boivin, T., Bouvier, J.C. \& Renou, M. (2007) Insecticide resistance may enhance the response to a host-plant volatile kairomone for the codling moth, Cydia pomonella (L.). Naturwissenschaften 94, 449-458.

Schumacher, P., Weyeneth, A., Weber, D.C. \& Dorn, S. (1997a) Long flights in Cydia pomonella L. (Lepidoptera: Tortricidae) measured by a flight mill: influence of sex, mating status and age. Physiological Entomology 22, 149-160.

Schumacher, P., Weber, D.C., Hagger, C. \& Dorn, S. (1997b) Heritability of flight distance for Cydia pomonella. Entomologia Experimentalis et Applicata 85, 169-175.

Shel'Deshova, G.G. (1967) Ecological factors determining distribution of the codling moth Laspeyresia pomonella (Lepidoptera: Tortricidae). Entomological Review 46, 349-361.

Soleño, J., Anguiano, L., de D'Angelo, A.P., Cichon, L., Fernandez, D. \& Montagna, C. (2008) Toxicological and biochemical response to azinphosmethyl in Cydia pomonella L. (Lepidoptera: Tortricidae) among orchards from the Argentinian Patagonia. Pest Management Science 64, 964-970.

Soleño, J., Anguiano, O.L., Cichon, L.B., Garrido, S.A. \& Montagna, C.M. (2012) Geographic variability in response to azinphos-methyl in field-collected populations of Cydia pomonella (Lepidoptera: Tortricidae) from Argentina. Pest Management Science 68, 1451-1457.

Stará, J. \& Kocourek, F. (2007) Insecticidal resistance and crossresistance in populations of Cydia pomonella (Lepidoptera: Tortricidae) in Central Europe. Journal of Economic Entomology 100, 1587-1595.

Steinberg, S., Podoler, H. \& Applebaum, S.W. (1992) Diapause induction in the codling moth, Cydia pomonella: effect of prediapause temperatures. Entomologia Experimentalis et Applicata 62, 131-137.

Tan, K., Chen, W., Dong, S., Liu, X., Wang, Y. \& Nieh, J.C. (2014) Imidacloprid alters foraging and decreases bee avoidance of predators. PLOS ONE 9, e102725. doi: 10.1371/journal. pone. 0102725 .

Torà, R., Dolset, A., Almacelles, J., Garcia de Otazo, J., Saló, X., Avilla, J., Bosch, D., Llombart, R., Batllori, L. \& Vilajeliu, M. (2009) Métodos alternativos de control de plagas. Confusión sexual para carpocapsa en manzano y peral. Dossier Técnico Formación y assessoramiento del sector agroalimentario 38, 8-17.

Tricoire-Leignel, H., Thany, S.H., Gadenne, C. \& Anton, S. (2012) Pest insect olfaction in an insecticide-contaminated environment: info-disruption or hormesis effect. Frontiers in Physiology 3, 1-6.

Trimble, R.M., El-Sayed, A.M. \& Pree, D.J. (2004) Impact of sub-lethal residues of azinphos-methyl on the pheromonecommunication systems of insecticide-susceptible and 
insecticide-resistant obliquebanded leafrollers Choristoneura rosaceana (Lepidoptera: Tortricidae). Pesticide Management Science 60, 660-668.

Vickers, R.A. \& Rothschild, G.H.I. (1991) Use of sex pheromone for control of codling moth. pp. 339-354 in van der Geest, L.P.S. \& Evenhuis, H.H. (Eds) Tortricid Pests: their Biology, Natural Enemies and Control. Elsevier, Amsterdam, The Netherlands.
Wei, H. \& Du, J. (2004) Sublethal effects of larval treatment with deltamethrin on moth sex pheromone communication system of the Asian corn borer, Ostrinia furnacalis. Pesticide Biochemistry and Physiology 80, 12-20.

Zhou, H., Du, J. \& Huang, Y. (2005) Effects of sublethal doses of malathion on responses to sex pheromones by male Asian corn borer moths, Ostrinia furnacalis (Guenée). Journal of Chemical Ecology 31, 1645-1656. 